\title{
João Vicente Torres Homem: Descrição da Carreira Médica no Século XIX
}

\author{
LUIZ OTÁVIO FERREIRA *
}

\section{Introdução}

A institucionalização da medicina no Brasil tem sido um tema privilegiado nos estudos históricos sobre a ciência no País. A razão disso reside no fato de que é no âmbito do conhecimento biomédico que encontramos os exemplos mais significativos de organização bem-sucedida da atividade científica.

Sobre este tema o estudo de Nancy Stepan ${ }^{1}$ acerca da gênese da pesquisa científica no campo biomédico foi, sem dúvida, pioneiro e inspirou toda uma linha historiográfica sobre a ciência no Brasil. Interessada em investigar a história da ciência no País, Stepan definiu como estratégia de pesquisa "examinar algum ponto da história do Brasil onde tivesse ocorrido algum rompimento na indiferença tradicional pela ciência, e no qual a ciência começou a ser investigada com certo grau de sucesso". ${ }^{2}$

O ponto de rompimento identificado por ela foi a criação, no Rio de Janeiro, entre 1903 e 1909, de um centro de pesquisa experimental dirigido

* Pesquisador da Casa de Oswaldo Cruz; professor de Sociologia da UERJ; e doutorando em História Social da USP.

1. N. Stepan, Gênese e Evolução da Ciência Brasileira. Oswaldo Cruz e a Política de Investigação Científica e Médica, Rio de Janeiro, Editora Artenova, 1976.

2. Idem, p. 19. 
pelo médico Oswaldo Cruz. O Instituto de Manguinhos é considerado pela autora o marco zero da institucionalização da ciência no Brasil.

A institucionalização da medicina experimental significou, conforme argumenta Stepan, a superação de uma "forte tradição clínica", ${ }^{3}$ que tendia a afastar o interesse dos médicos pela pesquisa científica.

O meu argumento é que a idéia de que a institucionalização da medicina experimental ocorreu em oposição a uma forte tradição clínica é fecunda. No entanto, é necessário ir além da simples alusão. É preciso conhecer quais eram as especificidades da medicina clínica. Isto significa considerar essa "forte tradição clínica" não um mero obstáculo ao progresso da ciência, mas uma tradição científic $a^{4}$ plenamente institucionalizada e portadora de padrões de formação intelectual, carreira profissional e produção de conhecimento próprios, que podem ser descritos e analisados mediante o estudo das trajetórias dos membros da elite médica. ${ }^{5}$

O objetivo deste artigo é descrever e analisar esses padrões típicos da tradição clínica brasileira do século XIX por meio do estudo da trajetória de João Vicente Torres Homem (1837-1887), um dos mais destacados clínicos desse século.

\section{As orientações teóricas da tradição clínica}

Quais eram efetivamente as orientações teóricas transmitidas pelas instituições de ensino médico brasileiras na primeira metade do século XIX?

Sem dúvida, a medicina clínica francesa foi a principal referência científica do ensino médico brasileiro nesse período, principalmente até as reformas acadêmico-administrativas das Faculdades de Medicina do Rio de Janeiro e da Bahia, ocorridas entre 1879 e $1884 .{ }^{6}$

A medicina francesa era, então, revolucionada pelo que Michel Foucault denominou o "nascimento da clínica", ${ }^{7}$ marco epistemológico do surgimento da moderna ciência médica.

3. Idem, p. 61 .

4. . B. Barnes, T. S. Kuhn y las Ciencias Sociales, México, Fondo de Cultura Económica, 1986, esp. cap. I, pp. 21-46.

5. Sobre a noçāo de elite médica, ver G. Weisz, "The Medical Elite in France in the Early Nineteenth Century”, Minerva, vol. XXV, nos 1-2, Spring/Summer, 1987, pp. 150-71.

6. Sobre as reformas do ensino médico no século XIX, ver F. C. Edler, As Reformas do Ensino Médico e a Profissionalização da Medicina na Corte do Rio de Janeiro, 1854-1884, Dissertação de Mestrado, Faculdade de Filosofia, Ciências e Letras/USP, 1992.

7. M. Foucault, $O$ Nascimento da Clínica, Rio de Janeiro, Forense Universitária, 1977. 
A clínica definiu o novo modus operandi da medicina, estabelecendo três princípios basilares: a) reconhecer no indivíduo determinada doença mediante a observação e descrição minuciosa dos sintomas e signos; b) distinguir no cadáver uma patologia específica mediante a observação da alteração dos tecidos e órgãos internos; e c) combater a doença com terapêuticas racionais e comprovadamente eficazes.

Nizza da Silva ${ }^{8}$ ocupa-se em descrever as orientações teóricas vigentes no ensino médico-cirúrgico no Rio de Janeiro nos primórdios do século XIX. Destaca, de início, os compêndios de medicina prática, publicados em 1815 no Rio de Janeiro, de autoria do médico José Maria Bomtempo, professor de Medicina Prática, Matéria Médica e Farmácia na Academia Médico-Cirúrgica. Tais compêndios eram, na verdade, resumos simplificados do clássico da medicina nosológica, Nosographie Philosophique, publicado por Phillippe Pinel em 1798. (Pinel definiu a medicina como a "ciência dos sintomas". Segundo esta definição, um médico deveria ser capaz de identificar e classificar uma doença a partir de determinados indícios verificados no indivíduo enfermo.)

É possível, por intermédio da leitura dos textos de Pinel, conhecer as atitudes dos médicos brasileiros em face da doença no início do século XIX.

Ao estudante de medicina, na época, ensinava-se, fundamentalmente, identificar a doença e classificá-la segundo seus sinais evidentes. Ele não deveria em nenhum momento cogitar sobre suas causas internas. É certo que havia por parte dos médicos esse tipo de preocupação, mas tratava-se sempre de causas externas: clima, alimentação e estilo de vida.

Nizza da Silva observa também que os médicos, além de controlarem o sistema classificatório das doenças, precisavam ter o domínio da "arte de formular”, ou seja, do modo de prescrever os remédios necessários para a cura das doenças.

Para o ensino da "arte de formular" era utilizado o Novo Ensaio sobre a Arte de Formular, de J. M. Alibert. Segundo este autor, a correta prática da "arte de formular" exigia que o médico, ao prescrever a medicação, observasse, além dos sintomas morbosos, a "história de vida" do doente, seu sexo, idade, temperamento e costumes. Advertia sobre o excessivo número de remédios prescritos, muitos deles produzidos ainda segundo fórmulas obscuras ou secretas. Numa época em que a química fazia revolucionárias descobertas, a "arte de formular" deveria obedecer a determinadas regras objetivas. Alibert enume-

8. M. B. Nizza da Silva, Cultura e Sociedade no Rio de Janeiro (1808-1821), Sāo Paulo, Companhia Editora Nacional, 1978. 
ra 24 regras que recomendam desde a total abstenção do uso de remédios, até o estudo das reações individuais a um mesmo medicamento. ${ }^{9}$

A orientação teórica vigente no ensino médico-cirúrgico do Rio de Janeiro nas duas primeiras décadas do século XIX era, portanto, tributária da nosologia de Pinel.

A transformação, em 1832, das Academias Médico-Cirúrgicas do Rio de Janeiro e da Bahia em Faculdades de Medicina tornou mais amplo o espectro da influência da medicina clínica francesa.

A relação de livros, elaborada em 1834 pela comissão formada pelos professores Valladão Pimentel, Francisco Julio Xavier e José Martins da Cruz Jobim para constituir o acervo da recém-criada biblioteca da Faculdade de Medicina do Rio de Janeiro, é demonstrativa das orientações teóricas instituídas no novo curso médico.

A identificação dos autores citados permitiu constatar que a relação de livros contemplava as diferentes orientações teóricas (ou sistemas médicos como eram conhecidos) da medicina clínica francesa de então. Estão aí representados a nosologia (Pinel), a anatomoclínica (Crovisart, Bayle, Monfalcon, Bardier, Portal), o ecletismo (Andral, Trousseau, Louis), além de Broussais, que construiu uma doutrina própria. A única exceção, por não pertencer ao universo da medicina clínica francesa, é J. Brown, médico inglês que ficou conhecido no final do século XVIII por sua teoria da excitabilidade orgânica, ${ }^{10}$ muito difundida na Itália, Áustria e Alemanha.

Não obstante a diversidade de doutrinas médicas é possível uma classificação geral das orientações do pensamento médico no século XIX. Segundo Lain Entralgo, ${ }^{11}$ as diversas teorias médicas podem ser reduzidas a três distintas mentalidades: anatomoclínica, fisiopatológica e etiológica.

A anatomoclínica associava o quadro sintomático à lesão orgânica, considerava a doença como uma alteração da "forma orgânica" e enfatizava a pesquisa dos signos físicos capazes de revelar a existência e índole da lesão fundamental.

A fisiopatologia considerava a doença uma alteração do processo energético e do material sustentador da vida orgânica e valorizava a interpretação dos sintomas em oposição a descrição dos signos físicos.

9. Idem, pp. 134-5.

10. G. Canguilhem, “Uma Ideologia Médica Exemplar - O Sistema de Brown”, in Ideologia e Racionalidade nas Ciências da Vida, Lisboa, Ediçōes 70, 1977.

11. P. L. Entralgo, La Historia Clínica. Historia y Teoria del Relato Patográfico, Barcelona, Salvat Editores, 1950. 
A etiologia definia a enfermidade como conseqüência da ação de um agente causal específico. Os agentes etiológicos poderiam ser desde substâncias tóxicas presentes no meio ambiente até organismos vivos patogênicos.

Devido à influência quase exclusiva da medicina clínica francesa, o pensamento médico brasileiro da primeira metade do século XIX reproduziu aqui as controvérsias científicas que polarizavam o campo médico parisiense.

A polêmica médica francesa de maior repercussão no Brasil foi a disputa entre o brousseísmo, ou seja, a doutrina de Broussais, e o ecletismo médico, que teve vigência em Paris nas décadas de 1820 e 1830.

François Broussais, criador da "medicina fisiológica", foi o mais influente e radical médico francês dos anos 20 do século passado. Criticou simultaneamente a nosologia, a anatomoclínica e o ecletismo. ${ }^{12}$ Ele foi, até certo ponto, um continuador de Bichat, no que diz respeito ao estudo das lesões nos tecidos e órgãos, embora considerasse que elas apenas traduziam um desarranjo de funções. No entanto, ele pretendeu revolucionar toda a medicina. Procurou organizar um sistema médico "fisiológico" baseado em proposições simples que valeriam para toda e qualquer enfermidade. $\mathrm{Na}$ verdade, não existiriam doenças, mas sim "irritações" locais, cuja propagação se daria pelas "simpatias" existentes entre os órgãos.

As "irritações" poderiam ser ocasionadas por estímulos internos ou externos (clima, alimentação, comportamento moral), que sensibilizariam em excesso ou em escassez o organismo. As "irritações" seriam locais e se desenvolveriam no sentido de uma "inflamação" geral. Segundo Broussais, a maioria das doenças era uma manifestação da inflamação do aparelho digestivo chamada "gastroenterite".

Mas o que popularizou Broussais foi o seu método terapêutico. Ao contrário de Pinel, que confiava no poder curativo da natureza e preconizava uma medicina expectante, Broussais pregava a necessidade de intensas intervenções, baseadas no método "antiflogístico", que consistia no uso de sangrias, na aplicação de sanguessugas e na prescrição de dietas enérgicas.

O ecletismo médico foi o mais amplo e heterogêneo movimento médico francês da primeira metade do século XIX. Sua motivação baseava-se no crescente ceticismo dos médicos quanto à possibilidade de cura diante das elevadas taxas de mortalidade dos pacientes tratados nos hospitais, e no

12. J. F. Braunstein, Broussais et le Materialisme. Médicine et Philosophioe au XIX o Siècle, Paris, Méridiens Klincksieck, 1986. 
descrédito que nutriam em relação aos grandes sistemas médicos, principalmente ao brousseísmo. Foram ecléticos os médicos Pierre Charles Louis, Gabriel Andral e Armand Trousseau, referências constantes e obrigatórias na produção médico-científica brasileira do século XIX.

Os ecléticos tinham em comum a rejeição dos sistemas médicos dogmáticos e a valorização da experiência, entendida como o acúmulo de casos observados e mesmo de autópsias feitas. As estatísticas eram, para os adeptos do ecletismo, o fundamento da atividade médica. Os dados estatísticos seriam a única certeza do médico, que só deveria admitir cơmo método a observação, em oposição às hipóteses especulativas. Os médicos ecléticos pretendiam transformar a medicina em uma ciência exata. ${ }^{13}$

O discurso científico da medicina clínica ensinada na Faculdade de Medicina do Rio de Janeiro até 1870 ganha significado histórico justamente por estar circunscrito ao debate entre o brousseísmo e o ecletismo. É somente no final daquela década que novos temas relacionados ao advento da medicina experimental começam a repercutir significativamente no ambiente intelectual daquela instituição, irradiando-se pelo campo médico como um todo.

\section{A construção da carreira médica}

Uma elite médica começa a se constituir na Corte do Rio de Janeiro a partir de 1830. Sob o controle das autoridades do governo imperial, seus membros foram recrutados entre os professores remanescentes da extinta Academia Médico-Cirúrgica, clínicos e cirurgiōes dos hospitais militares e da Santa Casa da Misericórdia, sendo incorporado também um grupo de jovens médicos, todos recém-formados na Faculdade de Medicina de Paris. Eles compuseram o quadro de professores da Faculdade de Medicina (1832) e foram os membros fundadores da Academia de Medicina (1835).

A nova elite médica procurou estabelecer sua autoridade e controle sobre assuntos relativos ao exercício profissional da medicina, ensino médico, produção e validação do conhecimento médico e a organização da saúde pública, pelo menos no espaço geográfico da cidade do Rio de Janeiro. ${ }^{14}$ Ela

13. J. M. Lopez Piñero, Ciencia y Enfermedad en el Siglo XIX, Barcelona, Ediciones Península, 1985.

14. R. Machado et alli, Danação da Norma: A Medicina Social e a Constituição da Psiquiatria Social no Brasil, Rio de Janeiro, Ediçōes Graal, 1978. 
se empenhou, sobretudo, em produzir um conhecimento médico original, adaptado às condições climáticas, antropológicas e sociais brasileiras. Esse esforço resultou na publicação, em Paris (1844), do livro Maladies e Climat du Brésil. Statistique Médicale de cet Empire ${ }^{15}$ escrito pelo médico francês radicado no Rio de Janeiro, Xavier Sigaud.

Evidentemente, um padrão de carreira médica foi sendo constituído à medida que a elite médica se afirmava como grupo social. A análise da trajetória da primeira geração de catedráticos da Faculdade de Medicina ${ }^{16}$ do Rio de Janeiro (1830-1860) nos proporciona o conhecimento do padrão da carreira médica em seus aspectos relacionados à formação intelectual, trajetória profissional e produção de conhecimento.

Os primeiros catedráticos da Faculdade de Medicina do Rio de Janeiro se formaram exclusivamente em duas escolas, a Academia Médico-Cirúrgica do Rio de Janeiro e a Faculdade de Medicina de Paris, com predomínio desta última. Pelo menos dois professores freqüentaram as duas escolas médicas e um deles também formou-se em Letras pela Faculdade de Letras de Paris.

A conseqüência dessa formação intelectual foi a homogeneização do pensamento da elite médica, referido exclusivamente aos temas impostos pela medicina clínica francesa.

Quanto à trajetória profissional, a tendência foi a diversificação de atividades. A maioria dos professores não atuou somente no magistério e na clínica privada, voltando-se também para o exercício de outras funções como a de clínico e/ou cirurgião nos hospitais, direção de órgãos públicos responsáveis pela saúde pública ou a presidência de associações ou comissões científicas.

A posição institucional mais frequiente, a de médico da Imperial Câmara, foi, na verdade, uma sinecura. Tratava-se de cargo honorífico criado por ocasião da maioridade de D. Pedro II em 1840, e que visava estabelecer o quadro de médicos da corte imperial. Por outro lado, a direção da Junta Central de Higiene e a presidência da Academia Imperial•de Medicina eram posições institucionais de relativa importância, visto que cabia a elas normatizar o exercício da profissão médica e propor ações de medicalização da sociedade.

15. Este livro, que condensa o conhecimento médico produzido pela elite médica desde 1830 , tornou-se obra de referência, sendo constantemente citado nos mel hores dicionários médicos europeus do século XIX, principalmente nos verbetes de climatologia médica.

16. A primeira geração de catedráticos da Faculdade de Medicina do Rio de Janeiro foi formada por 14 médicos. Os dados biobibliográficos sobre eles foram coletados em S. Blake, Dicionário Bibliográfico Brasileiro, Brasília, Conselho Federal de Cultura, 1970. 
Os vínculos dos catedráticos com as instituições militares de saúde também foram relevantes. A medicina militar tinha importância estratégica na medida em que o Exército e a Marinha estavam empenhados em preservar a frágil unidade naciọnal ameaçada por convulsões políticas internas e externas. Além disso, a medicina militar, enquanto especialidade, era um pólo produtor de novos conhecimentos relacionados às condições de saúde nas colônias européias na América, África e Ásia. ${ }^{17}$

\begin{tabular}{ll}
\hline Postos Institucionais & № \\
\hline Chefe de Enfermaria da Santa Casa da Misericórdia & 3 \\
Cirurgião-Mor da Polícia da Corte & 1 \\
Cirurgião-Mor do Hospital Real Militar & 1 \\
Diretor da Academia de Belas Artes & 1 \\
Diretor da Faculdade de Medicina do RJ & 1 \\
Diretor da Junta Central de Higiene Pública & 1 \\
Diretor de Comissão Científica & 1 \\
Diretor do Hospital Central da Marinha & 1 \\
Diretor Geral de Saúde do Exército & 1 \\
Médico da Imperial Câmara & 8 \\
Médico do Hospital Central da Marinha & 1 \\
Presidente da Academia Imperial de Medicina & 1 \\
\hline
\end{tabular}

A carreira política também atraiu a primeira geração de catedráticos da FMRJ. Embora se saiba que os médicos enquanto grupo social específico constituíram uma minoria no conjunto da elite política do Império, ${ }^{18}$ a ocupação de cargos políticos foi um aspecto importante na trajetória dos catedráticos. Sete deles (50\%) foram membros do Conselho de Estado; outros dois ocuparam uma cadeira no Senado ou presidiram uma Província. Somados, verificamos que nove, ou seja, $64 \%$, dos catedráticos ocuparam postos situados no topo da carreira política do Império. As posições políticas intermediárias de deputado provincial e deputado geral, ocupadas, por vezes, por catedráticos foram, na verdade, uma via de acesso ao Senado ou à presidência de Província.

17. A. Castiglioni, História da Medicina, São Paulo, Companhia Editora, 1947, 2 vols., esp. vol. I, cap. XXII.

18. Para uma análise da carreira política no Império, ver J. M. de Carvalho, A Construção da Ordem: A Elite Política Imperial, Rio de Janeiro, Editora Campus, 1980. 


\begin{tabular}{ll}
\hline Postos Políticos & No \\
\hline Conselheiro do Império & 7 \\
Deputado Geral & 4 \\
Deputado Provincial & 2 \\
Presidente de Província & 1 \\
Senador do Império & 1 \\
\hline
\end{tabular}

Uma avaliação da produtividade intelectual da elite médica mostra que, ao contrário do que é afirmado pela historiografia da medicina no Brasil, havia uma razoável produção científica e o diletantismo e a retórica não imperavam de modo absoluto.

É evidente que não podemos utilizar os critérios atuais de avaliação da produtividade intelectual no caso em questão. É necessário reconhecer quais eram os padrões de produção científica vigentes entre os membros da elite médica quando da sua constituição.

Consultando os dados biobibliográficos dos primeiros catedráticos da FMRJ verificamos que a produção intelectual era diversificada. Os produtos intelectuais mais comuns eram as chamadas "memórias", as teses de concurso, os relatórios/planos técnicos, os discursos, os extratos de lições, os casos clínicos e, naturalmente, os livros e compêndios. Os principais veículos de. divulgação da produção intelectual dos catedráticos foram os poucos periódicos médicos em circulação no Brasil entre 1830 e 1870.

As chamadas "memórias" destacam-se não só pela quantidade como pelo conteúdo, normalmente de interesse clínico. Por seu intermédio, as principais questões práticas e teóricas relacionadas ao dia-a-dia da clínica eram divulgadas e debatidas. As "memórias" também ocupavam-se do principal tema científico da medicina brasileira ao longo do século XIX: a relação entre as epidemias reinantes (as febres) e o clima do Brasil.

Outro produto intelectual típico foram os extratos de lições. Eram reproduções de aulas proferidas pelos catedráticos feitas por estudantes a partir de suas anotações pessoais, sendo muitas vezes publicadas por iniciativa dos próprios alunos.

Os relatórios técnico-científicos também eram comuns, uma vez que aqueles médicos haviam sido os responsáveis pela formulação dos estatutos da Academia Imperial de Medicina e da Faculdade de Medicina, além de relatórios sobre o estado sanitário da cidade do Rio de Janeiro. Dentre esses documentos os mais importantes foram os relatórios científicos produzidos por Freire Alemão, responsável pela Seção de Botânica da Expedição 
Científica de Exploração que percorreu as províncias do nordeste brasileiro entre 1858-1859.19

Os discursos proferidos em ocasiões solenes eram considerados como produto intelectual relevante. Assim, os catedráticos que ocupavam postos institucionais importantes, como a direção da Faculdade de Medicina ou a presidência da Academia de Medicina, se utilizavam da capacidade oratória para exibir sua erudição e afirmar sua autoridade institucional e científica.

As teses de concurso também cumpriam um papel de distinção de seus autores, pois garantiam a eles a legitimidade dos postos que ocupavam. É importante lembrar que os concursos não eram uma prática comum nas instituições de ensino superior brasileiras do século passado, quando os postos de ensino eram distribuídos mediante nomeações políticas e apadrinhamentos. No entanto, quando ocorriam, os concursos eram acontecimentos extremamente valorizados e ocasionavam disputas muitos acirradas.

\begin{tabular}{lr}
\hline Produção Científica & No $^{\mathbf{0}}$ \\
\hline Memórias & 44 \\
Teses de Concurso & 9 \\
Relatórios Técnico-Científicos & 19 \\
Discursos & 15 \\
Livros & 6 \\
Extratos de Lições & 14 \\
Casos Clínicos & 8 \\
\hline
\end{tabular}

\section{A cátedra anunciada}

João Vicente Torres Homem nasceu na Corte do Rio de Janeiro em 23 de novembro de 1837. Era um dos sete filhos que tiveram Joaquim Vicente Torres Homem e Bernarda Angélica dos Santos.

O pai, Joaquim Vicente Torres Homem, nasceu em Campos, província do Rio de Janeiro, provavelmente na década de 1790, e faleceu na Corte do Rio de Janeiro a 9 de dezembro de 1858, justamente quando João Vicente concluía o curso de medicina na Faculdade do Rio de Janeiro. Estudou medicina e ciências físicas e naturais em Paris, e defendeu, em 1829, a tese

19. M. M. Lopes, As Ciências Naturais e os Museus no Brasil no Século XIX, Tese de Doutorado, FFLCH/USP, 1993, pp. 142-9. 
"De l'utilité de l'auscutation et la percussion dans le diagnostic de quelques maladies de la poitrine". O tema escolhido revela a adesão de Joaquim Vicente ao método de diagnóstico clínico desenvolvido por Coriscar e Laennec.

Pela posição de professor da Faculdade de Medicina podemos supor que tenha sido um dos divulgadores da auscultação e percussão como meios de diagnóstico entre os médicos brasileiros. Além disso, Joaquim Vicente foi presidente da Academia Imperial de Medicina, médico da Imperial Câmara e médico do Hospital Militar da Corte. Era irmão de Francisco Salles Torres Homem, também médico, mas que se notabilizou como literato e político.

A carreira médica de João Vicente Torres Homem foi, sem dúvida, muito beneficiada pela conversão desse capital social familiar em prestígio nos campos médico e político. Todavia, é interessante notar que Torres Homem optou por uma atividade estritamente médica que em nenhum momento foi desdobrada em carreira política ou na ocupação de cargos públicos, fato comum entre os membros da elite médica. Esta é a principal singularidade da carreira de Torres Homem se comparada com a dos primeiros catedráticos da Faculdade de Medicina.

Torres Homem ingressou na Faculdade de Medicina do Rio de Janeiro em 1853, tendo concluído o curso em 1858. Sua passagem pela Faculdade coincidiu com a alteração da vida institucional da mesma, decorrente da sanção de um novo estatuto em 28 de abril de 1854, que alterava a administração da instituição e aumentava o quadro docente. A partir daquela data a FMRJ perdia a autonomia garantida pelo estatuto provisório de 3 de outubro de 1832. Foram suprimidos os direitos de confeccionar os seus regulamentos internos, de mudar a seriação das matérias, de dispor de suas taxas e emolumentos em favor da biblioteca, de eleger o diretor e de sugerir ao Poder Legislativo os créditos necessários à melhoria dos laboratórios e gabinetes da Faculdade.

Foi criada uma nova categoria docente, a de "Opositor", e suprimida a de "Substituto". O curso médico passou a ter 18 cadeiras, quatro a mais do que anteriormente - foram acrescentadas as cadeiras de Anatomia Geral e Patológica, Patologia Geral, Química Orgânica e Farmácia.

$\mathrm{O}$ ano de 1858 foi, para Torres Homem, marcado por acontecimentos que viriam influenciar decisivamente o início de sua carreira. A morte do pai o obriga a assumir o consultório paterno, um dos mais prestigiados da Corte, e a responsabilidade pela manutenção da madrasta e dos irmãos menores. É, também, quando seu relacionamento com o professor de Clínica Interna, Manoel Valladão Pimentel, Barão de Petrópolis, torna-se mais intenso. O 
contato mais próximo de Torres Homem com o veterano professor da Faculdade e amigo de seu pai teve início no quinto ano do curso médico, em 1857. No ano seguinte ele passa a trabalhar com Valladão Pimentel na Enfermaria de Nossa Senhora da Conceição do Hospital da Santa Casa da Misericórdia.

O destaque dado pelos biógrafos de Torres Homem à sua relação de mestre/discípulo com Valladão Pimentel atesta a importância da mesma. $\mathrm{O}$ jovem médico beneficia-se da tutela intelectual daquele que teria sido "o maior clínico de seu tempo", chegando mesmo a "ser chamado de Hipócrates brasileiro". ${ }^{20}$ Foi na enfermaria chefiada por Valladão Pimentel e no Hospital Militar da Corte, onde foi também interno em 1858, que Torres Homem começou a adquirir a experiência clínica que viria a ser depois consagrada.

Sua carreira médica profissional tem início no ano de 1860 , quando ele foi nomeado, mediante concurso, para o lugar de Opositor da Seção de Ciências Médicas da Faculdade de Medicina do Rio de Janeiro. Logo depois é contratado para o cargo de médico adjunto do Hospital da Santa Casa da Misericórdia.

Desde a sua criação, em 1854, o lugar de Opositor foi uma posição que pouca atração exercia sobre os jovens médicos, sendo, portanto, pouco disputada. Em vários concursos o número de candidatos foi insuficiente para o preenchimento das vagas oferecidas. O salário de 1:200\$000 mais uma gratificação de igual valor era considerado baixo. Por sua vez, um professor catedrático recebia um salário de 2:000\$000 mais uma gratificação de 1:200\$000.

Dentro da hierarquia acadêmica a subordinação do Opositor ao seu respectivo catedrático era absoluta. Suas atividades, determinadas anualmente pela Congregação da Faculdade, eram eventualmente de ensino. $\mathrm{O}$ Opositor era uma espécie de serviçal do catedrático.

Nos cinco anos em que exerceu a função de Opositor, Torres Homem foi designado para cumprir as seguintes tarefas: revisor de teses e preparador das aulas de Química Mineral e Medicina Legal (1862); preparador das aulas de Química Mineral e Medicina Legal (1863); preparador das aulas de Química Orgânica e Farmácia (1864), e chefe de Clínica Interna (1865). Apesar do desprestígio atribuído à função de Opositor, esta era indispensável para qualquer pretendente a ocupar uma das cátedras da Faculdade.

20. O. D. Sattamini, Um Médico do Império: O Doutor Torres Homem, 1837-1887, Rio de Janeiro, Irmāos Pongetti Editores, 1957, p. 33. 
A renovação do quadro docente da Faculdade de Medicina do Rio de Janeiro começa a ocorrer a partir da reforma do ensino de 1854. Esta renovação, imposta pelo jubilamento ou morte de vários professores, indicava a passagem da primeira geração de catedráticos da Faculdade que ascendeu ao cargo na década de 1830 . Entre 1854 e 1865 quase todos os antigos professores foram substituídos por Opositores nomeados pelo governo por meio de um intrincado jogo de cooptação e influência política.

Preterido pelo governo nas nomeações para o preenchimento das vagas que iam surgindo, Torres Homem faz uma investida. Apresenta-se para o concurso convocado em 1865 para a cadeira de Higiene, o primeiro ocorrido na Faculdade desde 1854. A vaga foi disputada com Antonio Correia Souza Costa que dedicou sua tese ao concorrente e amigo Torres Homem. Da disputa saiu vitorioso Souza Costa com a tese: "Qual a Alimentação que Usa a Classe Pobre do Rio de Janeiro e a Influência sobre a Mesma?". O trabalho apresentado por Torres Homem, intitulado "Do Aclimatamento", de "original exibe apenas sua observação clínica”, avalia o biógrafo Sattamini. ${ }^{21}$

Torres Homem logo teria sua segunda e grande chance de alcançar a Cátedra. Com o pedido de aposentadoria apresentado pelo veterano professor Valladão Pimentel, ficava disponível a mais cobiçada de todas as cátedras, a de Clínica Interna.

Era dupla a importância desta cadeira: acadêmica, pois era a cadeira que encerrava o curso médico, dando ao aluno experiência clínica concreta nas enfermarias do Hospital da Santa Casa da Misericórdia; e simbólica, já que o sucessor de Valladão Pimentel herdaria o lugar ocupado por aquele que era considerado a maior expressão da medicina da Corte.

Conforme assinalado, Torres Homem mantinha relações de amizade e acadêmicas com Valladão Pimentel desde 1858. Provavelmente, foi por intermédio de Valladão Pimentel que Torres Homem chegou, em 1860, ao quadro de médicos efetivos da Santa Casa da Misericórdia. Para substituir provisoriamente Valladão Pimentel na Faculdade o escolhido foi o Opositor Torres Homem, nomeado em 1865 chefe de Clínica Interna. Tudo indicava que caberia a ele suceder o prestigiado mestre.

O concurso convocado para 1866 foi muito concorrido. Disputavam a vaga os Opositores Luiz Pientznauer, José Maria de Noronha Feital, José Joaquim da Silva e Torres Homem, todos de "muito peso médico e político", assegura o biógrafo Sattamini.

21. Idem, p. 65 . 
Dessa segunda "luta de inteligências" saiu vitorioso José Joaquim da Silva com a tese "Da Sangria em Geral e em Particular na Pneumonia e na Apoplexia Cerebral". Torres Homem obteve, novamente, o segundo lugar, com uma tese que versava sobre assunto idêntico.

O tema dissertado pelos dois concorrentes remete ao debate entre o brousseísmo e o ecletismo, presente no campo médico desde a década de 1830 como espécie de questäo obrigatória. ${ }^{22}$ Vejamos os argumentos centrais das teses e as estratégias utilizadas pelos concorrentes Torres Homem e José Joaquim da Silva.

Torres Homem apresenta-se respaldado por uma série de títulos. Era, além de Opositor da Seção de Ciências Médicas, membro titular da Academia Imperial de Medicina, membro correspondente da Sociedade de Ciências Médicas de Lisboa, sócio efetivo e membro do Conselho da Sociedade Auxiliadora da Indústria Nacional, médico do Hospital da Santa Casa da Misericórdia e da Casa de Saúde de Nossa Senhora da Ajuda.

Além disso, dedica sua tese a seu "sábio mestre e amigo", Manoel Valladão Pimentel. Com isso, ele queria emprestar autoridade a seus argumentos e ressaltar sua condição de discípulo, de seguidor das orientações do veterano médico.

Na primeira parte da dissertação, após discorrer sobre "quais são os efeitos primitivos e secundários das sangrias", Torres Homem desenvolve a base de seus argumentos a respeito das "indicações e contra-indicações" das sangrias, que se constituía na principal questão a ser discutida. Após resumir as idéias de Broussais a respeito das funções terapêuticas das sangrias, Torres Homem declara sua posição sobre o tema:

"Felizmente para a humanidade, três médicos de grande prestígio e ilustraçāo, armados de escapelo e diante de cadáveres, demostraram à luz da evidência a exageraçāo perniciosa do sistemático clínico do Grâce: Rostan, Chomel e Louis, servindo-se dos argumentos que thes forneciam os fatos, tiveram força bastante, senão para fazer baquear a doutrina de Broussais, pelo menos para diminuir muito o número de seus sectários. De entāo para cá, não só os brousseístas nāo avultam tanto, mas também os que existem nāo sāo muitos exagerados: foi este um importante serviço que prestou à ciência a escola organicista".

"Livres do jugo do sistema de Broussais, os médicos de todos os países, nestes últimos anos, estabeleceram regras e preceitos para o emprego das sangrias, e todos eles estāo de acordo a respeito de algumas indicaçōes e contra-indicaçōes para se tirar sangue de um organismo doente”.

22. P. Bourdieu, “Sistemas de Ensino e Sistemas de Pensamento”, in A Economia das Trocas Simbólicas, Sâo Paulo, Editora Perspectiva, 1987, p. 207. 
“Entre as indicaçōes e contra-indicaçōes da sangria, umas são independentes da moléstia, e fornecidas pela idade do doente, sua constituiçāo, seu temperamento, seus hábitos, suas idiossincrasias, as circunstâncias em que ele se acha colocado, etc. Outras se referem a alguns sintomas particulares, ao estado do pulso, aos caracteres apresentados pelo sangue etc. ${ }^{23}$

A referência aos nomes de Rostan, Chomel e Louis, dissipa qualquer dúvida quanto a opção de Torres Homem pelo ecletismo, opção legitimada pelo fato de ter sido esta também a postura do mestre Valladão Pimentel que, segundo Torres Homem, nas enfermarias da Santa Casa da Misericórdia, nunca mandou "sangrar um doente pela terceira vez". ${ }^{24}$

Os dados biográficos que consegui recolher sobre José Joaquim da Silva não foram muitos. Nasceu no Rio de Janeiro, em 1830, e morreu em Lambari, Minas Gerais, em 1894. Era filho de Joaquim José da Silva, catedrático de Patologia Interna da Faculdade de Medicina do Rio de Janeiro. Formou-se por esta mesma faculdade, em 1853, sendo nomeado Opositor em 1855. Foi, segundo Lycurgo Santos Filho, "um dos mais sagazes clínicos de seu tempo", porém, foi "pouco assíduo" às aulas da cadeira de Fisiologia que assumiu em 1877.25 Sua tese desenvolve argumentos semelhantes aos de Torres Homem quanto às "indicações e contra-indicações” das sangrias. Condena os excessos de Broussais e seus seguidores e sugere procedimentos comedidos quanto ao uso de emissões sangüíneas, tal como recomendado pelo ecletismo.

A decisão da banca foi favorável a José Joaquim da Silva. Todavia, o decreto governamental de 17 de agosto de 1866, dava a vitória, de fato, a Torres Homem, nomeado para a cadeira de Clínica Médica, na qual foi solenemente empossado em 30 de agosto daquele ano.

A descrição do concurso que conduziu Torres Homem à cátedra serve para mostrar o modo de funcionamento do mundo acadêmico da medicina brasileira de meados do século XIX.

Confrontados os dados empíricos a respeito do campo médico brasileiro do século XIX com o modelo teórico que descreve o campo científico como uma esfera social autônoma e auto-regulada, ${ }^{26}$ percebe-se que estamos

23. J. V. Torres Homem, Das Sangrias em Geral e em Particular na Pneumonia e na Apoplexia Cerebral, Rio de Janeiro, 1866, pp. 5, 6 e 7.

24. Idem, p. 10.

25. L. Santos Filho, História Geral da Medicina Brasileira, São Paulo, Hucitec/Edusp, 1991, p. 128.

26. P. Bourdieu, “O Campo Científico”, in R. Ortiz, org., Pierre Bourdieu: Sociologia, São Paulo, Ática, 1983. 
diante de um mundo acadêmico extremamente permeável a fatores de diferenciação econômica, social e política, onde a origem familiar, a fortuna e o poder têm um papel decisivo.

\section{Um espaço para a polêmica: a Gazeta Médica do Rio de Janeiro}

A mais importante atividade exercida por Torres Homem no campo médico antes de assumir a cátedra na Faculdade de Medicina, foi, sem dúvida, a de membro do conselho redator da Gazeta Médica do Rio de Janeiro, periódico que circulou na Corte de 1862 a 1864 . Trata-se, sem dúvida, de uma inovação em termos dos padrões tradicionais de carreira médica então vigentes.

A Gazeta Médica foi fundada e dirigida pelos Opositores Torres Homem, Mateus Andrade, Pinheiro Guimarães e Souza Costa. Foi o primeiro periódico médico não-oficial, ou seja, não vinculado à Academia Imperial de Medicina, capaz de se manter regularmente editado por um espaço de tempo considerável se comparado com a média de vida de empreendimentos semelhantes anteriores.

Na historiografia da medicina brasileira a Gazeta Médica do Rio de Janeiro surge, ao lado da Gazeta Médica da Bahia (1866), como um dos principais periódicos médicos do Império, responsável pela renovação da medicina brasileira daquele tempo. 27

Das intervençōes de Torres Homem na Gazeta Médica, selecionei aquelas que evidenciassem a função de crítico científico, ou seja, os artigos, comentários e resenhas cujos objetivos fossem opinar sobre e avaliar a produção médico-científica.

O artigo de estréia de Torres Homem na Gazeta Médica é uma avaliação crítica dos primeiros relatórios do Gabinete Estatístico do Hospital Geral da Santa Casa da Misericórdia. A função desse Gabinete, criado em 1860, era publicar anualmente o resumo das observações a respeito dos doentes tratados nas diversas enfermarias públicas daquele hospital.

Como já foi mencionado, a confecção de rigorosos quadros estatísticos sobre o fluxo e o resultado do tratamento dos doentes nos hospitais era, para o ecletismo, o principal instrumento do qual deveria dispor o médico no seu

27. R. Fernandes, "A Imprensa Médica no $2^{\circ}$ Império", Revista do Instituto Histórico e Geográfico Brasileiro, Anais do Congresso de História do Segundo Reinado, Rio de Janeiro, 1984. 
dia-a-dia. Por seu intermédio, poder-se-ia efetivamente saber as formas de tratamento comprovadamente eficazes e aquelas que deveriam ser abandonadas ou restringidas.

Nos hospitais da Corte, não obstante a difusão dos preceitos do ecletismo, essa prática ainda encontrava resistência por parte dos médicos. Torres Homem observa que a principal dificuldade verificada por Luiz da Silva Brandão, médico responsável pelo Gabinete Estatístico, foi a negativa dos colegas de fornecer dados precisos sobre os doentes tratados.

Em abril de 1863, Torres Homem publica sua primeira resenha de um livro científico. Ele analisa Ensaio Médico-Legal sobre os Ferimentos e Outras Ofensas Físicas, com Aplicação à Legislação Criminal Pátria, Seguido de Algumas Considerações sobre o Infanticídio, de José Soriano de Souza. Torres Homem louva a iniciativa do autor de publicar um trabalho científico, atitude rara nos meios médicos de então, além do mais em uma área (medicina legal) onde um "limitadíssimo número de médicos" pode se pronunciar com autoridade.

Como já havia feito nos comentários sobre os relatórios do Gabinete Estatístico, Torres Homem dedica a maior parte da resenha à refutação e correção de "alguns pontos que nos parecem controversos, e onde as nossas opiniōes não podem combinar". ${ }^{28}$

A condição de crítico científico, exercida por Torres Homem nas páginas da Gazeta Médica, envolve-o não somente em polêmicas a respeito de conteúdos científicos, como também em lutas institucionais típicas de qualquer campo de produção intelectual. No caso, refiro-me às controvérsias entre a Gazeta Médica e a Academia Imperial de Medicina.

Uma das inovações instituídas pela Gazeta Médica foi a publicação, seguida de comentários, de resumos das sessões ordinárias da Academia Imperial de Medicina. Tais resumos eram produzidos pelos membros do conselho redator do periódico presentes nas sessões da Academia. Essa prática criou rivalidades entre os membros da Academia e os redatores da Gazeta Médica. Muitos acadêmicos tiveram o desprazer de ver suas idéias ou opiniōes questionadas pelo quarteto de jovens médicos que dirigia o periódico.

A tensão era crescente. Em 15 de julho de 1863, o debate torna-se público por meio de um editorial assinado por Torres Homem, que comenta a sessão

28. J. V. Torres Homem, O Ensaio Médico-Legal sobre os Ferimentos e Outras Ofensas Físicas, com Aplicaçāo à Legislação Criminal Pátria, Seguido de Algumas Consideraçōes sobre o Infanticídio. Obra especialmente dirigida às autoridades criminais por José Soriano de Souza, Gazeta Médica do Rio de Janeiro, $\mathrm{n}^{\mathrm{2}} 7,1^{\circ} \mathrm{de}$ abril de 1863. 
solene comemorativa do $27^{\circ}$ aniversário da Academia e responde às críticas feitas pelo secretário e fundador da instituição, De-Simoni, à Gazeta Médica.

A atuação do jornal em relação à Academia foi o assunto principal daquela reunião. Segundo o relato de Torres Homem, o presidente da instituição, Antonio Félix Martins, saiu em defesa da Gazeta, elogiando e agradecendo as apreciações feitas sobre as atividades da Academia. Já a opinião do secretário De-Simoni não foi, segundo Torres Homem, exatamente a mesma.

Torres Homem acusa De-Simoni de hostilizar o periódico colocando-se ao lado dos "encarniçados inimigos do nosso humilde jornal", 29 e pergunta sobre que interesses poderiam ter os redatores da Gazeta Médica em hostilizar a entidade. $O$ que interessava aos seus membros era fazer do periódico uma instância portadora de autoridade científica dentro do campo médico. Desse modo, era inevitável o confronto com os representantes das instituições científicas oficiais. Tal conflito tinha uma função distributiva, uma vez que, por seu intermédio, a autoridade científica podia ser disputada $e$, conseqüentemente, a estrutura do campo modificada.

Segundo o próprio Torres Homem, a Gazeta Médica tinha como sua "mais gloriosa tarefa $[\ldots]$ discutir com franqueza as opiniōes emitidas no recinto da única associação médica do país por homens que gozam de grande nomeada, pelos talentos que os recomendam, já pela posição oficial que ocupam". ${ }^{30}$

A polêmica com os representantes da "posição oficial" era a única estratégia de legitimação possível. Em carta dirigida ao próprio Torres Homem, e publicada pela Gazeta em setembro de 1863, De-Simoni desmentiu as acusações de antipatia para com os redatores do periódico. Este episódio antecedeu ao pedido formal de ingresso, como membro titular, na Academia dirigido por Torres Homem em 26 de outubro de 1863, acompanhado de uma memória sobre "a importância fisiológica do baço".

Está registrado no Annaes Brasiliense de Medicina, órgāo oficial da Academia, de fevereiro de 1864, o parecer do acadêmico Noronha Feital a respeito do pedido de Torres Homem. Segundo ele, as vagas existentes para o lugar de membro titular deveriam ser prioritariamente ocupadas pelos médicos que já eram membros adjuntos da Academia. ${ }^{31}$

29. J. V. Torres Homem, “A Sessāo Solene Aniversária da Academia Imperial de Medicina”, Gazeta Médica do Rio de Janeiro, $\mathrm{n}^{\circledR}$ 14, 15 de julho de 1863, p. 164.

30. Ibidem.

31. Sessāo Geral de 26 de outubro de 1863, Annaes Brasiliense de Medicina, ano 15, vol. 15, 9 de fevereiro de 1864, p. 197. 
Apesar desse parecer desfavorável, Torres Homem alcançaria seu objetivo. Na Sessão Geral de 7 de dezembro de 1863 foi lido o relatório do acadêmico João Batista dos Santos favorável à admissão de Torres Homem. A seguir, por meio de votação secreta, os outros acadêmicos aprovaram por unanimidade $o$ ingresso de Torres Homem como membro titular. Restava apenas, como exigia a lei, que o governo referendasse a decisão, o que efetivamente ocorreu em 12 de dezembro de 1863.

Em 1864 a Gazeta Médica do Rio de Janeiro deixou de ser publicada. Torres Homem encerra sua participação no periódico após alcançar novas posições de alto valor simbólico e autoridade científica suficiente para iniciar outras lutas no campo médico, inclusive aquela que o conduziria a uma cátedra na Faculdade de Medicina.

\section{Conclusão: a fidelidade ao paradigma clínico}

Mesmo com a extinção da Gazeta Médica do Rio de Janeiro, Torres Homem continuou sendo assíduo nos periódicos médicos, que tiveram seu número incrementado nas décadas de 1870 e 1880 - ele foi um incentivador e um dos colaboradores mais freqüentes dos mesmos. Entre 1873 e 1883, Torres Homem publicou 13 "memórias", estando entre os dez médicos de maior produtividade.

As "memórias" publicadas por Torres Homem, muitas vezes baseadas em notas de aulas recolhidas por seus alunos, foram agregadas em livros que se tornaram clássicos da medicina clínica da época. Os famosos Anuários de Observações Colhidas nas Enfermarias da Clínica Médica da Faculdade de Medicina do Rio de Janeiro (1868), Elementos de Clínica Médica (1870), Estudos Clínicos sobre as Febres do Rio de Janeiro (1877), Liçōes sobre as Moléstias do Sistema Nervoso (1878) e Lições de Clínica Médica (1882-18841889), são exemplares como expressã̀o do conhecimento e das questões científicas que organizavam a medicina clínica brasileira na época.

Fiel ao paradigma da medicina anatomoclínica e, particularmente, ao ecletismo, Torres Homem associava metodicamente o diagnóstico feito por meio da leitura dos sintomas ao exame anatomopatológico realizado em minuciosas autópsias.

Sua fidelidade ao modelo clássico da medicina clínica fez dele um poderoso opositor da medicina baseada na idéia da etiologia específica das doenças (bacteriologia e parasitologia). Seu estudo sobres as febres no Rio de Janeiro foi uma tentativa de elaboração de uma tipologia dessas epidemias, tendo se baseado no modelo nosológico e fundamentado na teoria da 
relaçāo intrínseca entre clima e doenças. Torres Homem nunca admitiu a veracidade da teoria microbiana das doenças elaborada por Lou is Pauster.

Torres Homem também ficou ao lado da tradição clínica na polêmica entre os médicos do Rio de Janeiro e os representantes da chamada Escola Tropicalista Bahiana sobre a etiologia de uma doença então denominada hipoemia intertropical, ${ }^{32}$ doença intestinal de origem parasitária hoje conhecida como ancilostomose. O nome hipoemia intertropical foi criado pelo médico e catedrático da primeira geração da Faculdade de Medicina do Rio de Janeiro José Martins da Cruz Jobim.

Em 1835, Cruz Jobim proferiu na Academia Imperial de Medicina uma palestra intitulada "As doenças que mais afligem a classe pobre do Rio de Janeiro”, em que descreveu a sintomatologia, patogenia, evolução clínica e terapêutica de um tipo singular de moléstia cujas características eram uma profunda anemia e o hábito compulsivo de comer terra. Segundo Jobim esta doença era causada pela ação deletéria do clima tropical sobre o sangue.

Embora fossem conhecidos os estudos de Dubini, que em 1843 encontrou em autópsia um verme nematóide, que pela sua forma e localização foi denominado Ancylostoma duodenale, e de Griesinger, que em 1852 também localizou o parasita, foi somente com as pesquisas de Otto Wucherer, realizadas na Bahia em 1866, que a teoria parasitária da doença foi aplicada ao caso da hipoemia intertropical.

A descoberta de Wucherer foi discutida na Academia Imperial de Medicina e após votação foi rejeitada por unanimidade. Torres Homem foi um dos críticos mais contundentes das idéias de Wucherer. Mesmo depois de a origem parasitária da doença ser reconhecida como correta, Torres Homem continuou afirmando que os ancilóstomos duodenais eram uma conseqüência e não o agente causal da doença.

Com certeza a postura ortodoxa de Torres Homem não foi um obstáculo intransponível para que as teorias microbiana e parasitária das doenças fossem difundidas pelo campo médico brasileiro. No entanto, ela é elucidativa para a compreensão das negociaçōes e controvérsias científicas que pontuaram a institucionalização da medicina experimental no Brasil.

32. Sobre a história da hipoemia intertropical, ver A. Lutz, A Opilação ou Hypoemia Intertropical e sua Origem, Rio de Janeiro, Typografia e Lithografia de Machado \& C., 1888. 


\section{RESUMO}

\section{João Vicente Torres Homem:}

Descrição da Carreira Médica no Século XIX

O objetivo deste artigo é descrever e analisar os padrões típicos de carreira médica instaurados no Brasil do século XIX, mediante o estudo da trajetória de João Vicente Torres Homem (1837-1887). A institucionalização da medicina clínica significou a vigência de um padrāo de formação intelectual, carreira profissional e de produção de conhecimentos distinto daqueles que vieram a ser implantados com a organização das primeiras instituiçōes médicas dedicadas à pesquisa científica no início do século XX.

\section{ABSTRACT}

João Vicente Torres Homem:

A Description of the Medical Career in Nineteenth-Century Brazil

By examining the case study of João Vicente Torres Homem (1837-87), the article describes and analyzes typical patterns in medical careers as established in nineteenth-century Brazil. The institutionalization of clinical medicine brought the prevalence of a pattern in intellectual training, professional careers, and the production of knowledge that differed from those patterns inaugurated in the early twentieth century upon organization of the first medical institutes dedicated to scientific research.

\section{RÉSUMÉ}

\section{João Vicente Torres Homem:}

La Carrière Médicale au XIXème Siècle

Cet article décrit et analyse les types de carrière médicale existant au Brésil au XIXème Siècle. Pour cela il étudie le cas de la carrière professionnelle de João Vicente Torres Homem (1837-1887). Lorsque la médecine clinique a été institutionnalisée, le modèle de formation intellectuelle, la carrière professionnelle et la production de connaissances ont adopté des caractères bien différents de ceux qui ont été établis lors de l'organisation des premières institutions médicales de recherche scientifique au début du XXème Siècle. 
